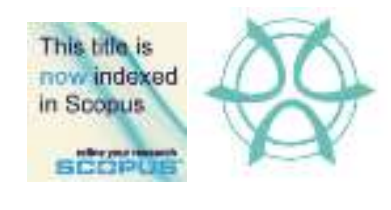

\title{
PUBLIC AWARENESS AND ACCEPTANCE TOWARDS TRANSPORTATION LOW CARBON CITY PROGRAMME. A COMPARISON STUDY OF MBSA AND DBKL
}

\author{
Na'asah Nasrudin ${ }^{1}$, Ainatul Isnoriza George ${ }^{2}$, Yusfida Ayu Abdullah ${ }^{3}$, \\ Marlyana Azyyati Marzukhi ${ }^{4}$, Oliver Hoon Leh Ling ${ }^{5}$, Kushairi Rashid ${ }^{6}$ \\ 1,2,3,4,5,6 Faculty of Architecture, Planning and Surveying, \\ UNIVERSITI TEKNOLOGI MARA (UiTM)
}

\begin{abstract}
This paper examines public awareness and acceptance towards Transportation Low Carbon City's (LCC) programme by two local authorities: Kuala Lumpur City Hall (DBKL) and Shah Alam City Council (MBSA). This paper also will measure the residents' satisfaction level on the LCC programme initiatives prepared by both authorities. The data were gathered through a survey conducted randomly from 202 respondents who represented the residents of Kuala Lumpur city and 122 respondents who represented the residents of Shah Alam city. The findings suggested that the awareness of the respondents about the Transportation LCC's programme was more positive in Kuala Lumpur as compared to Shah Alam. This was because almost 90 per cent of Kuala Lumpur respondents were aware of the programme. For feedback of willingness to change to non-motorised transportation as a support to Transportation LCC programme, Kuala Lumpur had a bright hope to fully achieve the successfulness of the LCC's programme as compared to Shah Alam. With regards to implementation of public transportation, the majority of the both respondents' groups agreed that the available public transportation was reliable, well-connected and reachable for their desired destination. This comparison study is essential to know how well the local authority manages their LCC programme. It is hoped that the two local authorities can learn and cooperate in future to make this programme a success.
\end{abstract}

Keywords: Low Carbon City, non-motorised transportation, public awareness and acceptance

${ }^{1}$ Senior lecturer. E-mail: naasa717@uitm.edu.my 
PLANNING MALAYSIA

Journal of the Malaysia Institute of Planners (2020)

\section{INTRODUCTION}

Over the last five years, it has shown that a growing trend of climate change and global warming has impacted the well-being of human beings and also, living things on the Earth. To address this issue, Malaysian Ministry of Energy, Green Technology and Water (2011) introduces Low Carbon City Framework to lead the reducing of the carbon emission from the main contributors which are greenhouse gases that consist of carbon dioxide (CO2). One of the biggest sources of human-caused greenhouse gas emissions responsible for a whopping 73 per cent worldwide, includes transportation sector.

Malaysia created Low Carbon Cities Framework (LCCF) in 2011 to guide Local Authorities in Malaysia, High Institute of Education and other regions in Malaysia to transform their cities into more greener cities, thus, making them popularly known as low carbon cities. The primary indicators of carbon emission, which are 'Urban Environment', 'Urban Infrastructure', 'Urban Transportation', and 'Buildings' are addressed in LCCF. Local Authorities are urged to implement LCCF and those who use it will successfully achieve low carbon city in their places. Most Local Authorities who implement LCCF usually look for local solution suppliers to satisfy their low carbon criteria and ambitions. LCCF is gradually implemented by Local Authorities. Those who have already adopted LCCF begin to work on more comprehensive and realistic strategies making the market demand for local approaches to grow. This will further boost the green local economy and speed up the transition to low carbon communities.

\section{LITERATURE REVIEW}

Public Perception, Awareness and Acceptance

Public perception is a proses of "the detection of information" (Michaels, 2000). The discrepancy between an absolute truth based on facts and a composite narrative formed by popular opinions, media coverage and credibility can be seen as a social phenomenon. Rao and Narayan (1998) defined perception as "a process, in which people select, organise, and interpret sensory stimulations into meaningful information about their work environment". Rao and Narayan (1998) elucidated that interpretation is the primary determinant of human behaviour, stating that "there can be no behaviour without perception." This can be inferred based on the concept specified that public perception is the process which defines human perceptions based on surrounding factors.

However, Dourish (1992) interpreted that awareness is "an understanding of the activities of others, which provides a context for your activity". Evidence has shown that the provision of awareness-raising resources increases the efficacy of how knowledge is distributed through populations (Gross, Stary, \& Totter, 2005) and also, significantly, impacts social interactions in those societies (Loevstrands, 1991). Ausserer and Risser (2005) also provided their thought that acceptance is 'a phenomenon that reflects how far potential 
Na'asah Nasrudin, Ainatul Isnoriza George, Yusfida Ayu Abdullah, Marlyana Azyyati Marzukhi, Oliver Hoon Leh Ling, Kushairi Rashid Public Awareness and Acceptance Towards Transportation Low Carbon City Programme. A Comparison Study of MBSA and DBKL

users are willing to use a certain system'. For Chirsmar and Wiley-Patton (2002), they stated that acceptance is an 'intention to adopt an application'. From all the definitions given, it can be inferred that public acceptance meets the need for the approval of something.

\section{Low Carbon City Programme in Shah Alam and Kuala Lumpur}

Low Carbon Cities 2030 Challenge (LCC2030C) sponsored by the Ministry of Energy, Science, Technology, Environment, and Climate Change (MESTECC), as well as GreenTech Malaysia is a new initiative aimed at promoting the transformation of our cities into low carbon cities. GreenTech Malaysia will work with Local Authorities to create low-carbon zones in the state capital and major urban areas across the country to ensure that the initiative achieves its objectives. Shah Alam City Council (MBSA) is a body responsible for managing Shah Alam Low Carbon City Programme. MBSA has successfully developed the 2030 Action Plan for Shah Alam Low Carbon City. This achievement symbolises the most influential contribution of the entire MBSA committee in its continuing efforts to maintain a green climate and comfortable atmosphere in Shah Alam as a Local Authority is concerned. 2030 Action Plan for Shah Alam Low Carbon City is designed to achieve the MBSA's goal of 'making Shah Alam a vibrant, green and productive city with an atmosphere that forms a society of environmental values. MBSA Low Carbon City 2030 Action Plan has outlined various actions in relation to transportation and mobility to ensure that Shah Alam achieves Low Carbon Transportation. MBSA establishes efficient transportation and mobility service, such as electric cars, e-parking, community buses, free bus service (Smart Selangor), preparation of cycling tracks, EV (electric vehicle) chargers in the area of Shah Alam, and free car days for all citizens of Shah Alam. MBSA also provides parking located in the area far from the city centre to encourage walking around the centre of the city, as well as to upgrade disabledfriendly walkways and covered pedestrian walkways.

In the meantime, Kuala Lumpur City Hall (DBKL) is the authority that is charge of LCC's programme in Kuala Lumpur (KL). It successfully produces Kuala Lumpur Low Carbon Society Blueprint 2030 (KL LCSBP 2030) as an initiative to take part in Low Carbon Cities 2030 Challenge (LCC2030C) launched on July 23, 2019. Dewan Bandaraya Kuala Lumpur (DBKL) aims to reduce the city's carbon emissions intensity of Gross Domestic Products (GDP) by 70 per cent in 2030 (based on the 2010 level) without compromising its vision and economic growth targets. One of the initiatives is to reduce private vehicles entering the city centre of Kuala Lumpur during peak hours. DBKL also enhances the use of effective variable message signs in delivering green information to the public. For example, with slogans of "Kuala Lumpur towards a Low Carbon City" and "Reduce Congestion; Together, We Use Public Transportation", DBKL tries to remind Kuala Lumpur residents every day about the importance 
PLANNING MALAYSIA

Journal of the Malaysia Institute of Planners (2020)

to reduce private car usage. This is done to show support to Transport Low Carbon City programme. 'Free Bus Rides within Downtown KL' during peak hours is also a good measure to encourage public transportation usage. On the weekends, DBKL has run 'Kuala Lumpur Car Free Morning Programme' to support the LCC initiatives. DBKL also creates dedicated cycle lanes in the downtown area of Kuala Lumpur to encourage Kuala Lumpur residents to use non-motorised transportation. Besides that, air-conditioned elevated walkways are run by solar energy to reduce carbon emission.

\section{Free Bus-initiaves of Transportation LCC Programme in Shah Alam and Kuala Lumpur}

Both cities, Shah Alam and Kuala Lumpur have implemented the free bus programme. For Shah Alam residents, Selangor Smart Bus (SSB) is operated by Selangor, Malaysia Berhad. The residents can have the bus service at a frequency of 15 minutes a stop from six in the morning to nine at night. Selangor Smart Bus has a total coverage of four routes (Shah Alam Commuter Station - Section 7, Nearest City Centre - Batu Tiga Commuter Station, Shah Alam Commuter Station - Sections 18-24, and Shah Alam Commuter Station - Sections 19-20) and a proposed new route (Terminal Section 17 - Section 7). In Kuala Lumpur, the free bus service is owned by Suruhanjaya Perkhidmatan Awam Malaysia (SPAD), and the operators are Transnational and Rapid Bus Consortia. This free service has been in place since August 31, 2012 and has expanded from two routes to four separate circular routes. These four separate circular routes can be identified by the colour of routes like Green, Purple, Red, and Blue. In early of 2019, the Orange and Pink routes were added. The Turquoise route was later added in October 2019. These free buses are open to residents and tourists, as well as the service can be used at the official bus stop of Go KL City Bus. Many bus stops are close to tourist attractions, major shopping centres, as well as easy accessibility by rail transit systems, like KTM Commuter, Rapid KL and Express Rail Link Sdn. Bhd. (ERL).

\section{RESEARCH METHOD}

This study tried to make a comparison in terms of public awareness and acceptance towards the Transportation LCC programme held by MBSA and DBKL. The residents' satisfaction level on the LCC programme initiatives prepared by both authorities was also measured in this study. LCC programme was introduced since 2011. There were various programmes conducted by Local Authority in Shah Alam and Kuala Lumpur, but some questions were raised, such as, "Is the system linked to society?" and "Does the system really include all the residents?" From the public's response, the authorities would consider his or her concerns, as well as recommendations in gaining his or her cooperation and involvement to ensure that the programme worked and benefited others. 
Na'asah Nasrudin, Ainatul Isnoriza George, Yusfida Ayu Abdullah, Marlyana Azyyati Marzukhi, Oliver Hoon Leh Ling, Kushairi Rashid Public Awareness and Acceptance Towards Transportation Low Carbon City Programme. A Comparison Study of MBSA and DBKL

The method used was questionnaire to obtain the data from Shah Alam and Kuala Lumpur. One hundred and twenty-two respondents had taken part to answer the questionnaire distributed in Shah Alam, as well as two hundred and two respondents had taken part to answer the questionnaire distributed in Kuala Lumpur. The questionnaire was in a form of paper-based survey with several subitems. It was distributed to the respondents to gauge their understanding, interpretations and approval about the Shah Alam Low Carbon Transportation system. The sub-items asked the respondents to evaluate the programme interest, support and anticipation.

Details about background information of the respondents (such as age and gender), public transportation usage, walk and cycle among respondents, low carbon in own vehicle uses, and respondents' opinion on Transportation LCC programme were compared and highlighted. Scale of data measurement was reported in percentage and rating scale comparison.

\section{THE RESULTS AND FINDINGS}

\section{i. Comparison of the Awareness about LCC Programme by MBSA and DBKL}

The survey that was conducted on 122 respondents in Shah Alam showed that 55 per cent of the respondents were not aware of the LCC programme, while only 45 per cent of them were aware of the programme. Based on cross-tabulation analysis for comparing the awareness between the gender, it displayed that females $(71 \%)$ were more likely to be aware of the LCC programme than men (29\%). Nevertheless, it had been noticed that in Kuala Lumpur, only 17 per cent of the respondents were not aware of the LCC programme, while 83 per cent of the respondents were mindful of the effort to the LCC programme. The findings from a comparison analysis between the gender in Kuala Lumpur exhibited that the male respondents were more aware (64\%) than the female respondents (36\%). The comparison of the data could be seen in Table 1.0.

Table 1.0: The awareness of LCC programme comparison according to gender in Shah

\begin{tabular}{|l|c|c|c|c|c|c|c|c|c|c|c|c|c|}
\multicolumn{10}{c|}{ Llam and Kuala Lumpur respondents } \\
\hline \multirow{3}{*}{ Gender } & \multicolumn{9}{|c|}{ LCCP Awareness } & \multicolumn{2}{c|}{ Total Respondents } & \multicolumn{3}{c|}{$\%$} \\
\cline { 2 - 15 } & \multicolumn{3}{|c|}{ Shah Alam } & \multicolumn{3}{c|}{ Kuala Lumpur } & \multicolumn{2}{c|}{$\%$} \\
\cline { 2 - 13 } & Aware & $\%$ & $\begin{array}{c}\text { Not } \\
\text { aware }\end{array}$ & $\%$ & Aware & $\%$ & $\begin{array}{c}\text { Not } \\
\text { Aware }\end{array}$ & $\%$ & SA & KL & SA & KL \\
\hline Male & 16 & 29 & 26 & 39 & 108 & 64 & 4 & 11 & 42 & 112 & 34 & 55 \\
\hline Female & 39 & 71 & 41 & 61 & 60 & 36 & 30 & 89 & 80 & 90 & 66 & 45 \\
\hline
\end{tabular}




\begin{tabular}{|c|c|c|c|c|c|c|c|c|}
\hline $\begin{array}{c}\text { Awareness } \\
\text { Percentage }\end{array}$ & $\begin{array}{c}55 \\
(45 \%)\end{array}$ & $\begin{array}{c}67 \\
(55 \%)\end{array}$ & $\begin{array}{c}168 \\
(83 \%)\end{array}$ & $\begin{array}{c}34 \\
(17 \%)\end{array}$ & 122 & 202 & 100 & 100 \\
\hline
\end{tabular}

\section{i. Comparison of the Awareness about the Provision of Public Transportation in Shah Alam and Kuala Lumpur}

a. Awareness of Free Bus in Shah Alam and Kuala Lumpur According to Age Group

Table 1.1 demonstrates the residents' awareness about the availability of free bus according to their age group. The majority of the age range between 20 to 40 years in Shah Alam and Kuala Lumpur were aware of the free bus service provided in their places. It could be said that the residents in these age groups had the potential to use the bus as their primary mode of transportation.

Table 1.1: Awareness of the Shah Alam and Kuala Lumpur Free Bus Service According to Age

\begin{tabular}{|c|c|c|c|c|}
\hline \multirow[t]{2}{*}{ Age group } & \multicolumn{2}{|c|}{ Shah Alam Free Bus Awareness } & \multirow[b]{2}{*}{ Total } & \multirow[b]{2}{*}{$\%$} \\
\hline & Aware & Not Aware & & \\
\hline 15-19 years & 5 & 1 & 6 & 5 \\
\hline 20-29 years & 48 & 5 & 53 & 43 \\
\hline 30-39 years & 38 & 0 & 38 & 31 \\
\hline 40-49years & 10 & 0 & 10 & 8 \\
\hline $50-59$ years & 10 & 0 & 10 & 8 \\
\hline 60-64 years & 2 & 0 & 2 & 2 \\
\hline 65 above & 0 & 3 & 3 & 2 \\
\hline $\begin{array}{l}\text { Percentage of } \\
\text { awareness }\end{array}$ & $\begin{array}{c}113 \\
(93 \%)\end{array}$ & $\begin{array}{c}9 \\
(7 \%)\end{array}$ & 122 & 100 \\
\hline \multirow[t]{2}{*}{ Age Group } & \multicolumn{2}{|c|}{$\begin{array}{c}\text { Kuala Lumpur Free Bus } \\
\text { Awareness }\end{array}$} & \multirow[t]{2}{*}{ Total } & \multirow[t]{2}{*}{$\%$} \\
\hline & Aware & Not Aware & & \\
\hline $15-20$ years & 1 & 0 & 1 & 1 \\
\hline 21-30 years & 54 & 3 & 57 & 28 \\
\hline $31-40$ years & 61 & 5 & 66 & 33 \\
\hline $41-50$ years & 26 & 21 & 47 & 23 \\
\hline $51-60$ years & 23 & 0 & 23 & 11 \\
\hline $61-70$ years & 7 & 1 & 8 & 4 \\
\hline $\begin{array}{l}\text { Percentage of } \\
\text { awareness }\end{array}$ & $\begin{array}{c}172 \\
(85 \%)\end{array}$ & $\begin{array}{c}30 \\
(15 \%)\end{array}$ & 202 & 100 \\
\hline
\end{tabular}


Na'asah Nasrudin, Ainatul Isnoriza George, Yusfida Ayu Abdullah, Marlyana Azyyati Marzukhi, Oliver Hoon Leh Ling, Kushairi Rashid Public Awareness and Acceptance Towards Transportation Low Carbon City Programme. A Comparison Studyof MBSA and DBKL

\section{b. Level of Convenience}

The study also collected data from the respondents of Shah Alam and Kuala Lumpur on the level of convenience and time they took to walk to the nearest station. This was done to determine the suitability of the bus station placement. From Table 1.2, it could be seen that 42 per cent of Shah Alam respondents stated that the time taken to walk to the nearest station was moderately convenient. In contrast, 32 per cent stated that it was 'not convenient' to walk to the nearest station, while 26 per cent stated that it was 'convenient' to walk to the nearest station. The data were then cross-tabulated with the time taken to walk to the station to observe whether the station was within walking distance for the respondents. It was found that the longest time taken to go to the nearest station was in a maximum time range of 11 to 15 minutes. This showed that the station was still within walking distance and it was still convenient to walk to the nearest public bus station. Meanwhile, for Kuala Lumpur, 62 per cent of the respondents said that the time taken to walk to the nearest bus station was also 'moderately convenient', while 16 per cent stated that it was 'not convenient' to walk to the nearest station. For the category of 'convenient' to walk to the nearest station, 22 per cent responded to that. From the cross-tabulation between the time taken and level convenience, the result indicated that although the time range of 10 to 20 minutes of walking was classified as the longest time to walk, Kuala Lumpur respondents still felt that it was moderately convenient for them to walk to the nearest bus station.

Table 1.2: Convenience Level and Walking Duration to the Nearest Bus Station among Shah Alam Respondents and Kuala Lumpur Respondents

\begin{tabular}{|c|c|c|c|c|c|}
\hline \multirow{2}{*}{$\begin{array}{l}\text { Walking Duration to } \\
\text { Nearest station }\end{array}$} & \multicolumn{3}{|c|}{ Shah Alam } & \multirow[b]{2}{*}{ Total } & \multirow[b]{2}{*}{$\%$} \\
\hline & Convenient & $\begin{array}{l}\text { Moderately } \\
\text { Convenient }\end{array}$ & $\begin{array}{c}\text { Not } \\
\text { Convenient }\end{array}$ & & \\
\hline $1-5$ minutes & 9 & 4 & 4 & 17 & 14 \\
\hline 6-10 minutes & 15 & 12 & 5 & 32 & 26 \\
\hline $11-15$ minutes & 8 & 14 & 14 & 36 & 30 \\
\hline 16-30 minutes & 0 & 10 & 15 & 25 & 20 \\
\hline 30 minutes above & 0 & 11 & 1 & 12 & 10 \\
\hline Total & $\begin{array}{c}32 \\
(26 \%)\end{array}$ & $\begin{array}{c}51 \\
(42 \%)\end{array}$ & $\begin{array}{c}39 \\
(32 \%)\end{array}$ & 122 & 100 \\
\hline \multirow{2}{*}{$\begin{array}{l}\text { Walking Duration to } \\
\text { Nearest station }\end{array}$} & \multicolumn{3}{|c|}{ Kuala Lumpur } & \multirow[b]{2}{*}{ Total } & \multirow[b]{2}{*}{$\%$} \\
\hline & Convenient & $\begin{array}{l}\text { Moderately } \\
\text { Convenient }\end{array}$ & $\begin{array}{c}\text { Not } \\
\text { Convenient } \\
\end{array}$ & & \\
\hline 3- 5 minutes & 4 & 39 & 8 & 51 & 25 \\
\hline 5-10 minutes & 17 & 8 & 0 & 25 & 12 \\
\hline
\end{tabular}


PLANNING MALAYSIA

Journal of the Malaysia Institute of Planners (2020)

\begin{tabular}{|l|c|c|c|c|c|}
\hline $10-20$ minutes & 24 & 62 & 12 & 98 & 49 \\
\hline $20-30$ minutes & 0 & 16 & 12 & 28 & 14 \\
\hline Total & 45 & 125 & 32 & & \\
& $(22 \%)$ & $(62 \%)$ & $(16)$ & 202 & 100 \\
\hline
\end{tabular}

\section{ii. Comparison of the Awareness about the Provision of Cycling Tracks in Shah Alam and Kuala Lumpur}

MBSA had prepared a cycling track, which is two kilometres long and ten feet wide. The cycling track has a premix finishing and is located in a green area in Section 4 on the edge of a residential area. The amenities provided together with the bicycle track are two gazebos, ten outdoor gym equipment units, three bridges, information signs, safety signs, signboards, and safety railings. The cycling track in Section 4 is designed around the neighbourhood. Some of the cycling tracks are designed to pass through the alleys and the back lanes of houses. They are complete with safety railings to protect cyclists from vehicle road users. In Kuala Lumpur, DBKL had provided the cycle lanes at Southwest Dedicated Bicycle Highway, in which the first motorcycle route was officially open for a new Cycling Kuala Lumpur programme. They are two more official cycle lanes in Kuala Lumpur are located at Taman Tun Dr Ismail and Wangsa Maju. The cycle lanes in Kuala Lumpur are not well connected to any residential areas to allow people to commute from their homes.

Table 1.3: Awareness on Provision of Cycling Lanes According to Bike Ownership

\begin{tabular}{|c|c|c|c|c|}
\hline \multirow[t]{2}{*}{$\begin{array}{l}\text { Bicycle } \\
\text { Ownership }\end{array}$} & \multicolumn{2}{|c|}{$\begin{array}{c}\text { Awareness on Provision of Cycle } \\
\text { Lanes in Shah Alam }\end{array}$} & \multirow{2}{*}{$\begin{array}{c}\text { Total } \\
\text { Respondents }\end{array}$} & \multirow[t]{2}{*}{$\%$} \\
\hline & Aware & Not Aware & & \\
\hline Owned bicycle & 37 & 21 & 58 & 48 \\
\hline $\begin{array}{l}\text { Did not own } \\
\text { bicycle }\end{array}$ & 36 & 28 & 64 & 52 \\
\hline $\begin{array}{l}\text { Percentage of } \\
\text { awareness }\end{array}$ & $\begin{array}{c}73 \\
(59 \%)\end{array}$ & $\begin{array}{c}49 \\
(41 \%)\end{array}$ & 122 & 100 \\
\hline \multirow[t]{2}{*}{$\begin{array}{l}\text { Bicycle } \\
\text { Ownership }\end{array}$} & \multicolumn{2}{|c|}{$\begin{array}{l}\text { Awareness on Provision of Cycle } \\
\text { Lanes in Kuala Lumpur }\end{array}$} & Total & $\%$ \\
\hline & Aware & Not Aware & Respondents & \\
\hline Owned bicycle & 45 & 17 & 62 & 31 \\
\hline $\begin{array}{l}\text { Did not own } \\
\text { bicycle }\end{array}$ & 80 & 60 & 140 & 69 \\
\hline $\begin{array}{l}\text { Percentage of } \\
\text { awareness }\end{array}$ & $\begin{array}{c}125 \\
(62 \%)\end{array}$ & $\begin{array}{c}77 \\
(38 \%)\end{array}$ & 202 & 100 \\
\hline
\end{tabular}


Na'asah Nasrudin, Ainatul Isnoriza George, Yusfida Ayu Abdullah, Marlyana Azyyati Marzukhi, Oliver Hoon Leh Ling, Kushairi Rashid Public Awareness and Acceptance Towards Transportation Low Carbon City Programme. A Comparison Study of MBSA and DBKL

As shown in Table 1.3, majority of the respondents in Shah Alam and Kuala Lumpur were aware of the provision of cycle lanes in their cities. Nonetheless, with regards to bicycle ownership, only 31 per cent of the respondents who owned a bicycle in Kuala Lumpur and Shah Alam gained a higher number of bicycle ownership which was 48 per cent. The difference was not so much significant, and it could be said that the status of bike ownership did not balance the preparation of the cycling track by the respondents. In other words, the existence of the cycling track was not good enough to encourage people to own a bicycle and use the facilities.

\section{iii. Comparison of the Spreading Medium for the Promotion of LCC Programme in Shah Alam and Kuala Lumpur}

In terms of the method to promote and spread the medium of the LCC programme by MBSA and DBKL, there was a huge difference. This was because MBSA gained more attention by using social media, while DBKL gained more attention by using flyers. Figure 1.0 shows the percentage of the type of spreading medium identified between the respondents from Shah Alam and Kuala Lumpur about the LCC programme. For Shah Alam, the highest rate of 65.6 per cent was through social media, followed by 34.4 per cent through flyers, 21.9 per cent through friends and family, as well as 15.6 per cent through newspapers, while the remaining was only 3.1 per cent through other medias. In Kuala Lumpur, flyers exhibited the highest percentage of 50 per cent, followed by newspapers with 21 per cent, friends and family with 10 per cent, social media with 5 per cent, and other spreading mediums with 4 per cent.
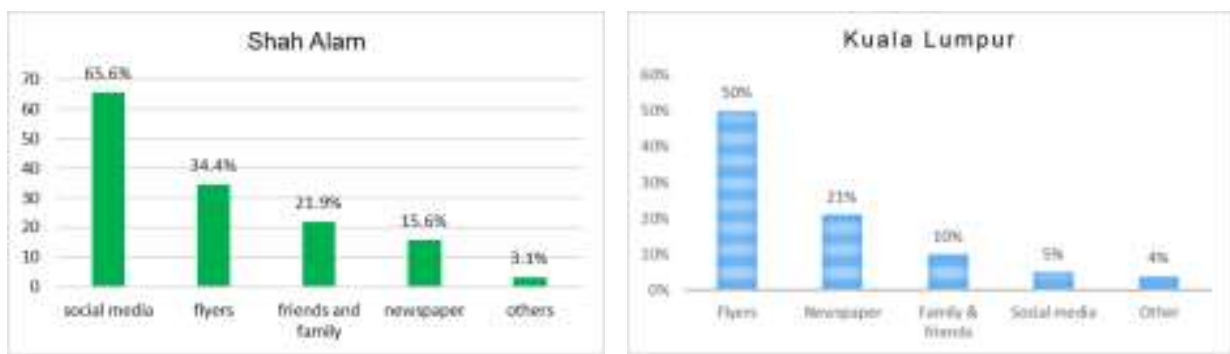

Figure 1.1: LCC's Program Promotion and Spreading Medium between MBSA (Shah Alam) and DBKL (Kuala Lumpur)

\section{iv. Comparison of the Policy Suggested by Respondents in Reducing Private Car Usage in Shah Alam and Kuala Lumpur}


In encouraging the residents in Shah Alam and Kuala Lumpur to support and be involved in the LCC programme, the respondents were asked to select a policy that could encourage them to reduce private car usage. Table 1.4 shows the policies chosen by the respondents from both of the cities. The policy of subsidising electric car had the highest percentage as chosen by the respondents, followed by the policy of subsidising public transportation fee and the policy of increasing parking charge. The policy that had the lowest frequency as chosen by the respondents was the policy to increase the fuel price.

Table 1.4: Policy Suggested by Respondents in Reducing Private Car Usage between Shah Alam and Kuala Lumpur Residents

\begin{tabular}{|l|c|c|c|c|}
\hline Policy & Shah Alam & $\%$ & Kuala Lumpur & $\%$ \\
\hline Subsidising electric car & 62 & 51 & 116 & 57 \\
\hline $\begin{array}{l}\text { Subsidising public } \\
\text { transportation fee }\end{array}$ & 35 & 29 & 56 & 28 \\
\hline Increasing parking charge & 21 & 17 & 20 & 10 \\
\hline Increasing fuel price & 4 & 3 & 10 & 5 \\
\hline \multicolumn{1}{|r|}{ Total } & 122 & 100 & 202 & 100 \\
\hline
\end{tabular}

\section{v. Comparison of the Mode Change Acceptance for Non- Motorised Transportation in Shah Alam and Kuala Lumpur}

Table 1.5 displays that the differences were quite significant for the readiness to change to non-motorised transportation between Shah Alam and Kuala Lumpur respondents. There were 40 per cent of the respondents who were 'ready' to switch to non-motorised in Shah Alam, and there were 60 per cent of the respondents who were not prepared to change. Different than in Kuala Lumpur, 45 per cent of the respondents were 'ready' to change to non-motorised followed by 37 per cent of the respondents who responded 'maybe' with the chance of readiness to change. Lastly, 18 per cent of Kuala Lumpur respondents stated that they were 'not ready' to change to non-motorised transportation. This showed that the respondents in Kuala Lumpur were readier to transform to non-motorised transportation than the respondents in Shah Alam.

Table 1.5: Mode Change Acceptance for Non-Motorised Transportation between Shah Alam and Kuala Lumpur Respondents

\begin{tabular}{|l|c|c|}
\hline \multirow{2}{*}{ Readiness } & \multicolumn{2}{|c|}{ Shah Alam } \\
\cline { 3 - 4 } & Frequency & Percentage (\%) \\
\hline Ready & 49 & 40 \\
\hline Not Ready & 73 & 60 \\
\hline & 122 & 100 \\
\hline
\end{tabular}


Na'asah Nasrudin, Ainatul Isnoriza George, Yusfida Ayu Abdullah, Marlyana Azyyati Marzukhi, Oliver Hoon Leh Ling, Kushairi Rashid Public Awareness and Acceptance Towards Transportation Low Carbon City Programme. A Comparison Study of MBSA and DBKL

\begin{tabular}{|l|c|c|}
\hline \multirow{2}{*}{ Readiness } & \multicolumn{2}{|c|}{ Kuala Lumpur } \\
\cline { 2 - 3 } & Frequency & Percentage (\%) \\
\hline Ready & 90 & 45 \\
\hline Maybe & 75 & 37 \\
\hline Not Ready & 37 & 18 \\
\hline & 202 & 100 \\
\hline
\end{tabular}

\section{vi. Comparison of the Feedback Regarding LCC Programme in Shah Alam and Kuala Lumpur}

Based on Table 1.6, the respondents were asked about three elements concerning the MBSA and DBKL programmes, namely, the approach, the implementation and the participation. From the ratings, it could be seen that all three elements had an average rate based on the feedback from the respondents. It could also be seen that the number of participations in the LCC programme in Kuala Lumpur was low, with 58 respondents as compared to the number of participations in Shah Alam. Therefore, DBKL must work harder in encouraging people to participate in its programme.

Table 1.6: Feedback Regarding Transport LCC Programme in Shah Alam and Kuala Lumpur

\begin{tabular}{|l|c|c|c|}
\hline \multirow{2}{*}{ Elements } & \multicolumn{3}{|c|}{ Shah Alam } \\
\cline { 2 - 4 } & Good & Average & Poor \\
\hline Approach & 55 & 55 & 12 \\
\hline Implementation & 30 & 66 & 26 \\
\hline Participation & 49 & 63 & 10 \\
\hline \multirow{2}{*}{ Elements } & \multicolumn{3}{|c|}{ Kuala Lumpur } \\
\cline { 2 - 4 } & Good & Average & Poor \\
\hline Approach & 65 & 97 & 2 \\
\hline Implementation & 55 & 107 & 58 \\
\hline Participation & 51 & 76 & \\
\hline
\end{tabular}

\section{vii. Comparison of the Support for Upcoming Programme by Age Group in Shah Alam and Kuala Lumpur}

From Table 1.7, 74 per cent of the respondents were willing to support the upcoming LCC programme in Shah Alam. Table 1.7 indicates that 38 per cent of the respondents who were willing to support the forthcoming programme were from the age group of 20 to 29 years old. For Kuala Lumpur, 50 per cent of the respondents supported the programme, and 50 per cent of the respondents might support the programme. The highest percentage of supporting this programme $(42 \%)$ was shown by the age group of 21 to 30 years old. A similar scenario was also seen in Shah Alam as the highest percentage of supporting this programme 
(38\%) was shown by the age group of 20 to 29 years old. Thus, it could be concluded that the young adults with the age range of 20 to 30 years old were willing to support the upcoming LCC programme in Shah Alam and Kuala Lumpur.

Table 1.7: Support for Upcoming Programme by Age Group between Shah Alam and Kuala Lumpur

\begin{tabular}{|c|c|c|c|c|c|c|c|c|}
\hline \multirow{2}{*}{$\begin{array}{l}\text { Age Group } \\
\text { (Years) }\end{array}$} & \multicolumn{8}{|c|}{ Upcoming Programme Support in Shah Alam } \\
\hline & Support & $\%$ & Maybe & $\%$ & Not Support & $\%$ & Total & $\%$ \\
\hline $15-19$ & 5 & 6 & - & - & 1 & 100 & 6 & 5 \\
\hline $20-29$ & 34 & 38 & 19 & 61 & - & - & 53 & 43 \\
\hline $30-39$ & 28 & 31 & 10 & 32 & - & - & 38 & 31 \\
\hline $40-49$ & 9 & 10 & 1 & 3 & - & - & 10 & 8 \\
\hline $50-59$ & 10 & 11 & - & - & - & - & 10 & 8 \\
\hline $60-64$ & 2 & 2 & - & - & - & - & 2 & 2 \\
\hline 65 above & - & - & 3 & 10 & - & - & 3 & 2 \\
\hline Total & \multicolumn{2}{|c|}{$\begin{array}{c}90 \\
(74 \%)\end{array}$} & \multicolumn{2}{|c|}{$\begin{array}{c}31 \\
(25 \%)\end{array}$} & \multicolumn{2}{|l|}{$\begin{array}{c}1 \\
(1 \%)\end{array}$} & 122 & 100 \\
\hline \multirow{2}{*}{$\begin{array}{l}\text { Age Group } \\
\text { (Years) }\end{array}$} & \multicolumn{8}{|c|}{ Upcoming Programme Support in Kuala Lumpur } \\
\hline & Support & $\%$ & Maybe & $\%$ & Not Support & $\%$ & Total & $\%$ \\
\hline $15-20$ & 1 & 1 & 0 & 0 & - & - & 1 & 1 \\
\hline $21-30$ & 42 & 42 & 15 & 15 & - & - & 57 & 28 \\
\hline $31-40$ & 23 & 23 & 43 & 43 & - & - & 66 & 33 \\
\hline $41-50$ & 22 & 22 & 25 & 25 & - & - & 47 & 23 \\
\hline $51-60$ & 7 & 7 & 16 & 16 & - & - & 23 & 11 \\
\hline $61-70$ & 6 & 6 & 2 & 2 & - & - & 8 & 4 \\
\hline Total & \multicolumn{2}{|c|}{$\begin{array}{c}101 \\
(50 \%)\end{array}$} & \multicolumn{2}{|c|}{$\begin{array}{c}101 \\
(50 \%)\end{array}$} & \multicolumn{2}{|l|}{ - } & 202 & 100 \\
\hline
\end{tabular}

\section{SUMMARY AND CONCLUSION}

The findings from survey indicated that 55 per cent of the Shah Alam respondents were not aware of the LCC programme, while only 45 per cent of them were aware of the programme. Although LCC programme had been noticed in Kuala Lumpur, 17 per cent of the respondents were not aware of the LCC programme, while 83 per cent of the respondents were mindful of the effort to the LCC programme.

With regards to provision of transportation facilities to support the LCC programme, the majority of the residents in Shah Alam and Kuala Lumpur were aware of the provision of free bus service in their places. The survey showed that the residents in the age group of 20 to 40 years old had the potential to use the bus as their primary mode of transportation. The results were also similar for awareness on the provision of cycle lanes. Conversely, for bicycle ownership, only a few of them owned a bicycle. This implied that the status of bike ownership 
Na'asah Nasrudin, Ainatul Isnoriza George, Yusfida Ayu Abdullah, Marlyana Azyyati Marzukhi, Oliver Hoon Leh Ling, Kushairi Rashid Public Awareness and Acceptance Towards Transportation Low Carbon City Programme. A Comparison Study of MBSA and DBKL

did not balance with the preparation of the cycling tracks. It could be observed that the existence of the cycling track was not good enough to encourage people to own a bicycle and use the facilities.

In encouraging the residents in Shah Alam and Kuala Lumpur to support and be involved in the LCC programme, the respondents were asked to select the policy that could encourage them to reduce private car usage. The findings showed that the respondents had a high preference on the policy of subsidising electric car, followed by the policy of subsidising public transportation fee and the policy of increasing parking charge. The policy that had the lowest preference by the respondents was the policy to increase the fuel price.

Pertaining to readiness to change to non-motorised transportation, Kuala Lumpur respondents were prepared to transform to non-motorised transportation as compared to the Shah Alam respondents. On a contrary, 74 per cent of the Shah Alam respondents were willing to support the upcoming LCC programme. From respondents' opinions about the LCC programme approach, the implementation and the participation of Transportation LCC Programme from both authorities, it was found that all three elements had an average rate based on the feedback from the respondents. Therefore, a few strategies need to be developed to ensure the success of the Transportation LCC programme implemented by both Local Authorities, namely, MBSA and DBKL.

\section{ACKNOWLEDGEMENT}

The authors would like to thank Universiti Teknologi MARA (UiTM) for the support. The authors would also like to thank all the departments, organisations and individual who had contributed to this study.

\section{REFERENCES}

Ausserer, K. and Risser, R. (2005). Intelligent Transport systems and services - chances and risks. Proceedings of 18th ICTCT-workshop Helsinki, Finland.

Chismar and Wiley-Patton (2002). Does the Extended Technology Acceptance Model Apply to Physicians, Proceedings of the 36th Hawaii International Conference on System Sciences (HICSS'03)?

Dourish, P. and Bellotti, V. (1992). Awareness and Coordination in Shared Workspaces. Proceedings of the 1992 ACM conference on Computer-supported cooperative work, CSCW '92, pp. 107-114, New York, NY, USA.

Gross, T., Stary, C., and Totter, A. (2005). User-Centered Awareness in ComputerSupported Cooperative Work-Systems: Structured Embedding of Findings from Social Sciences. International Journal of Human-Computer Interaction, 18(3):323-360.

KeTTHA (Ministry of Energy, Green Technology and Water Malaysia) (2011). Low Carbon Cities Framework \& Assessment System. Putrajaya. 
Loevstrand, L. (1991). Being Selectively Aware with the Khronika System. Proceedings of the Second European Conference on Computer-Supported Cooperative Work ECSCW'91.

Michaels, C. F. (2000). Information, perception, and action: What should ecological psychologists learn from Milner and Goodale (1995)? Ecological Psychology, 12, 241-258.

Rao, V. S. P. and Narayana, P. S. (1998), Organisation Theory and Behaviour, pp. 329330, Delhi: Konark Publishing Company.

Received: $15^{\text {th }}$ May 2020. Accepted: $1^{\text {st }}$ Sept 2020 